The conclusions that were drawn from our unique clinical story are as follows:

- Medical inventors and researchers are enthusiastic for the use of their experimental drugs in clinical situations.

- The weakest aspect of evidence-based medicine is the 'lack of evidence' in the related particular clinical problem. This represents a great challenge, particularly for real-life medical emergencies.

- Sometimes medical doctors have to make clinical decisions despite the lack of solid scientific evidence in the presence of urgent medical needs.

- Rat and animal studies may be the only source of evidence for human use in some medical emergencies.

- Nevertheless, the best clinical practice should rely on the best current evidence obtained through randomized controlled clinical trials.

Keywords: Ankaferd, Burn, Physician patient, Mucosal healing

Anahtar Sözcükler: Ankaferd, Yanık, Doktor hasta, Mukozal iyileşme

Informed Consent: Informed consent was obtained from the patient included in the study.
Conflict of Interest: No benefits in any form have been received or will be received from a commercial party related directly or indirectly to the subject of this article.

\section{References}

1. Patıroğlu $T$, Şahin NE, Ünal $E$, Kendirci $M$, Karakükcü $M$, Özdemir MA. Effectiveness of Ankaferd BloodStopper in prophylaxis and treatment of oral mucositis in childhood cancers evaluated with plasma citrulline levels. Turk J Hematol 2018;35:85-86.

2. Haznedaroglu BZ, Beyazit Y, Walker SL, Haznedaroglu IC. Pleiotropic cellular, hemostatic, and biological actions of Ankaferd hemostat. Crit Rev Oncol Hematol 2012;83:21-34.

3. Gorgulu S, Norgaz T, Sipahi I. Ankaferd blood stopper as a new strategy to avoid early complications after transradial procedures: a randomized clinical trial. J Interv Cardiol 2018;31:511-517.

4. Kaya H, Gokdemir MT, Sogut O, Demir T, Koçarslan S. Effects of folk medicinal plant extract Ankaferd Blood Stopper on burn wound healing. Acta Medica Mediterr 2013;29:497-502.

5. Akalin C, Kuru S, Barlas AM, Kismet K, Kaptanoglu B, Demir A, Astarci HM, Ustun $\mathrm{H}$, Ertas E. Beneficial effects of Ankaferd Blood Stopper on dermal wound healing: an experimental study. Int Wound J 2014;11:64-68.

6. Ozcan E, Senol S, Tokgoz Y, Kuloglu T. The regenerative effects of hemostatic plant extract in second degree burn wound. Ulutas Med J 2017;3:78-84.

7. Marshall BJ. The 1995 Albert Lasker Medical Research Award. Helicobacter pylori: the etiologic agent for peptic ulcer. JAMA 1995;274:1064-1066.

๑Copyright 2018 by Turkish Society of Hematology

Turkish Journal of Hematology, Published by Galenos Publishing House

\title{
Hematology Laboratory Survey
}

\author{
Hematoloji Laboratuvar Anketi
}

\author{
(D) Rujittika Mungmunpuntipantip1, (D) Viroj Wiwanitkit² \\ 126 Medical Center, Clinic of Hematology, Bangkok, Thailand \\ ${ }^{2}$ Dr. DY Patil University, Pune, India
}

\section{To the Editor,}

We read the publication "Results of the Hematology Laboratory Survey: What Has Changed in Eight Years?" with great interest. Kozanoğlu et al. [1] noted that "Hematology laboratories have not been defined in the Turkish Medical Laboratories Regulation (2010, 2013), which regulates procedures and principles regarding the planning, licensing, opening, regulating, classifying, monitoring, controlling, and terminating of activities of medical laboratories". We would like to share ideas from our country in Indochina. In Thailand, there is no isolated hematology laboratory. All clinical hematology investigation is performed by a standard clinical laboratory medicine center [2]. Routine laboratory survey and quality surveillance for accreditation is the basic requirement. This might be a good way for quality control of laboratory processes. Indeed, there is a need for clinical pathologists or clinical hematologists for the management of a hematology laboratory. This is necessary for the assurance of the quality of laboratory diagnoses. The concept of isolated hematology and combination with other clinical laboratories in a single laboratory medicine unit is an 
interesting topic for further discussion of the advantages and disadvantages.

Keywords: Hematology, Laboratory, Survey

Anahtar Sözcükler: Hematoloji, Laboratuvar, Anket

Conflict of Interest: The authors of this paper have no conflicts of interest, including specific financial interests, relationships, and/or affiliations relevant to the subject matter or materials included.

\section{References}

1. Kozanoğlu I, Patıroğlu T, Dalva K, Yanıkkaya Demirel G, Soysal T, Demir M. Results of the hematology laboratory survey: what has changed in eight years? Turk J Hematol 2018;35:215-216.

2. Charuruks N, Vanavanitkun $Y$, Seublinvong $T$, Werawatanakumpa $S$, Eiam-Oung S, Jindamaporn A, Chirathaworn C, Panyavorawuch V, Ruangvejvorachai $P$. Situation of laboratory service and instruments in Thailand: a descriptive study from questionnaires. J Med Assoc Thai 2002;85(Suppl 1):253-261.

\section{Reply to the Authors}

\section{To the Editor,}

We read the letter from Mungmunpuntipantip and Wiwanitkit regarding our publication on "Results of the Hematology Laboratory Survey: What Has Changed in Eight Years?"

First of all, we would like to thank the authors, that they have shared their experiences and ideas from their country. We understood that all clinical hematology investigation was performed by a standard clinical laboratory medicine center in Indochina and also, there is no isolated hematology laboratory in their country.

We all agree that the concept of isolated hematology and combination with other clinical laboratories in a single laboratory medicine unit is an interesting topic for further discussion on advantages and disadvantages. Many hematology laboratories have closed and/or were included into a central laboratory system after starting new regulations in Turkey. The authors also agree with us that there is a need for the clinical hematologist for management of the hematology laboratory. However, after the new regulations in our country, the managers of hematology laboratories became biochemistry specialists. But it is very important to evaluate specific tests in the hematology laboratory and to integrate them with the clinical status of patients. Therefore, the removal of clinical hematologists from hematology laboratories was a significant disadvantage. The routine laboratory survey and quality surveillance for accreditation is the basic requirement not only for hematology laboratories but also in all laboratories. However, after the new regulations implemented, only the quality issues will not be sufficient to solve problems related to hematology laboratories in Turkey.

Best Regards, İlknur Kozanoğlu, Türkan Patıroğlu, Klara Dalva, Gülderen Yanıkkaya Demirel, Teoman Soysal, Muzaffer Demir 